\title{
TOMOGRAFIA COMPUTADORIZADA DE FEIXE CÔNICO (CONE BEAM) EM ODONTOLOGIA: ATUALIDADES E TENDÊNCIAS
}

Mariane Zanin MAZZUTTI, Daniel Paludo BRUNETTO, Ademir Roberto BRUNETTO

A tomografia computadorizada de feixe cônico (TCFC) é uma tecnologia recente e inovadora que vem ganhando espaço na odontologia moderna, porém ainda traz consigo algumas dúvidas com relação à sua aplicabilidade e confiabilidade. O objetivo deste trabalho é provar a sua fidelidade e acurácia, incitando confiança no cirurgião-dentista e dando conhecimento a este para utilizá-la nas suas mais diversas aplicações, que são citadas. Além disso, são apresentadas várias imagens renderizadas em 3D geradas pelo software Dolphin Imaging 3D. Essas imagens são geradas e manipuladas na própria clínica, a partir de um CD formato DICOM, e acrescentam muitas informações de grande valor para o ortodontista, proporcionando então melhor diagnóstico e plano de tratamento. Conclui-se que a TCFC tem precisão e fidelidade suficientes para ser utilizada na odontologia e o seu uso tende a crescer tanto na rotina clínica como também em pesquisas. Ela tem possibilitado grande avanço na prática ortodôntica, pois entre outros fatores possibilitou o desenvolvimento de uma cefalometria 3D. Portanto, devido à sua qualidade superior de imagens e à visualização em 3D (nos planos axial, sagital e coronal) que proporciona, cria novos conceitos na odontologia, gerando promissor campo para pesquisas futuras e conduzindo o cirurgião-dentista à excelência clínica.

Palavras-chave: Tomografia computadorizada de feixe cônico; Cefalometria; Diagnóstico. 